\title{
"LIKE ME" DETECTION IN INFANCY: TOWARD UNDERSTANDING OTHER'S MENTAL STATES
}

\author{
Wakako SANEFUJI \\ Kyushu University, Japan Society for the Promotion of Science Research Fellow, Japan
}

\begin{abstract}
The first important step toward an understanding of the other's mental state involves identification of the other person. The ability of infants to detect humans and familiar individuals is present since the time of birth; moreover, infants prefer other infants of the same age in the sense that they are similar to the infants themselves. Recent developmental hypothesis assumes that the correspondence between the self and the other, that is, the recognition of other individuals as "like me (i.e., producing identical expressions and movements)" must play an important role in the development of understanding other's mental states. The aim of this article is to provide an overview of the previous literature on the social perception during infancy, with particular emphasis on the correspondence between the self and the other. Additionally, this paper discusses the role of such social perception in the subsequent development of understanding other's mental states.
\end{abstract}

Key words: infancy, "like me", social perception, imitation

The issue of how and when humans develop understanding others as psychological beings who have mental states is not merely a psychological issue; this has now become an interdisciplinary topic. Neuroimaging researches revealed that the superior temporal sulcus is related to the perception of other's motion (Puce \& Perrett, 2003) and the perception of other's intention (Saxe, Xiao, Kovacs, Perret, \& Kanwisher, 2004). Comparative behavioral studies suggested that ape social cognition are, in part, similar to human one in understanding what others do/do not see, or have/have not seen in the immediate past, as well as other's goal directed activities; however, other animal species including apes clearly do not have a human-like theory of mind (Tomasello, Call, \& Hare, 2003).

Human infants face to differentiate their surroundings from the early periods of their lives. The ability of infants to differentiate among other individuals enables them to establish a stable relationship and dyadic interaction with others including their caretakers. The initial social interaction for infants, the dyadic interaction, gradually develops into a triad communication with other individuals by using objects including toys. The sharing of attention with social partners in relation to objects or events, which is known as joint

I gratefully acknowledge Hidehiro Ohgami for his insightful comments on an earlier draft of the paper. I am also grateful to Andrew N. Meltzoff for his intellectual generosity and the fruitful discussions on both the empirical and theoretical issues raised in this article.

Correspondence concerning this article should be addressed to Wakako Sanefuji, Graduate School of Human-Environment Studies, Kyushu University, 6-19-1 Hakozaki, Higashi-ku, Fukuoka 812-8581, Japan (e-mail: wakko-s@mrh.biglobe.ne.jp). 
attention, is considered to be one of the important evidences of an infant's understanding of other's mind. Based on the conventional code (Adamson \& Bakeman, 1985) or penumbral background knowledge (Bruner, 1995) of each culture, joint attention behaviors such as pointing and gaze following emerge typically after around 9 months of age (e.g., Adamson \& Bakeman, 1985; Brooks \& Meltzoff, 2002; Bruner, 1983; Butterworth \& Jarret, 1991; Carpenter, Nagall, \& Tomasello, 1998; Tomasello, 1995). Toward the end of the first year, infants are able to interpret other's actions and share the intention in actions by, for example, giving or showing objects to others, imitating the actions of others, and engaging in social referencing (e.g., Meltzoff \& Moore, 1994; Sorce, Emde, Campos, \& Klinnert, 1985; Tomasello \& Furrar, 1986; von Hofsten \& Siddiqui, 1993). By the first half of the second year, infants begin to distinguish the surface behavior of people (what they actually do) from their deeper level (what they intended to do); fifteen-month-old infants were able to successfully convey the intention behind their actions even when the demonstrated actions were failed attempts (Bellagamba \& Tomasello, 1999; Meltzoff, 1995; Sanefuji, Hashiya, Itakura, \& Ohgami, 2004). Such rudimentary understanding of another's mental state correlates not only with language ability (e.g., Carpenter et al., 1998; Morales, Mundy \& Rojas, 1998; Morales, Mundy, Delgado, Yale, Neal \& Schwartz, 2000; Mundy \& Gomes, 1998), but also with later social cognitive abilities such as theory of mind (e.g., Carpenter et al., 1998; Meltzoff, 2005; Meltzoff \& Brooks, 2001).

The first important step toward such an understanding of another's mental state should be the ability to differentiate among other individuals. It is hypothesized that one of the key aspects of the ability to differentiate is the correspondence between self and the other; that is, the ability to recognize that others are "like me," which plays an important role in the development of understanding of the other person's mental state (e.g., Meltzoff \& Gopnik, 1993; Meltzoff \& Brooks, 2001). This study aims to provide an overview of previous studies regarding social perception during infancy. Then, by focusing on the correspondence between the self and the other, the role of such social perception in the subsequent development of social cognition such as the understanding of the other person's mental state is discussed.

\section{IDENTIFICATION OF OTHERS DURING INFANCY}

The ability to detect and recognize conspecifics is critical for the survival of a species, including humans. The recognition of humans is useful for the purpose of maintaining a social community and transmitting cultures; given the importance of maternal care that the community provides, it is natural to assume that the detection of humans is rooted in the early development of a child.

\section{Detection of humans}

In fact, the signs of social perception emerge almost immediately after birth. Within the first few days of life, infants are able to detect and selectively attend to the human 
face-like patterns when comparing with inverted or distorted patterns (e.g., Fantz, 1963; Johnson, Dziurawiec, Ellis, \& Morton, 1991; Maurer \& Young, 1983; Valenza, Simion, Macchi Cassia, \& Umiltà, 1996). These findings are suggestive of a rich innate ability within infants; additionally, developmental changes occur as a result of their use of this innate ability to interpret the social environment. Evolution has provided the human infant with "discovery procedures" for developing an adult common-sense psychology; however, the eventual psychological state is not specified at birth or through maturation alone (e.g., Gopnik \& Meltzoff, 1997; Meltzoff \& Brooks, 2001; Meltzoff \& Gopnik, 1993).

Additionally, infants are sensitive to human motions and this sensitivity develops during the ontogenetic process. For instance, infants are able to detect the motions depicting the human form when presented with point-light displays (PLDs) that are attached to the major joints and head of a person walking (Bertenthal, 1993). It was observed that even 3-month-old infants are able to discriminate the PLDs of human walkers from that of scrambled walkers (Bertenthal, Proffitt, \& Cutting, 1984; Bertenthal, Proffitt, \& Kramer, 1987; Proffitt \& Bertenthal, 1990) or the inverted orientation of PLDs (Fox \& Mcdaniel, 1982). The sensitivity to the PLDs of human walkers is manifested among infants between 4 and 6 months of age (Bertenthal, et al., 1987; Fox \& Mcdaniel, 1982). By 9 months, infants are able to interprete PLDs as an actual person merely discriminating between the PLDs of human and that of other nonhuman patterns (Bertenthal, Proffitt, Spetner, \& Thomas, 1985); the event-related potential studies also show that the neural substrates for processing human motions begin to mature around 8 months of age (Hirai \& Hiraki, 2005; Reid, Hoehl, \& Striano, 2006).

Such detection of humans is a fundamental cognitive ability of all human beings (Mervis \& Rosch, 1981). The ability to group humans into a particular category of natural objects guides their judgments of whether or not an event is expected to be caused by a human being. Along with a development in the interpretation of human motions, infants begin to differentiate and exhibit different responses between agents with psychological states (humans) and physical objects (Legerstee, 1992; Poulin-Dobois, 1999). For instance, 6-month-old infants spent longer time looking at a scene in which human agents talk to humans than at a scene in which human agents talk to objects; 4-month-old infants did not exhibit such differential responses (Molina, Van de Walle, Condry \& Spelke, 2004).

In sum, it appears to be evident that human infants have the ability to detect humans since the time of birth, deepen their interpretation of humans, and thus recognize human nature by around 6 months of age. Indeed, the period of around 6 months of age concurs with that when the infants are certainly able to engage in mutual dyadic interaction with their caretakers. The establishment of dyadic interaction with others should be considered against the background of such development on human understanding.

\section{Identification of others based on visual experiences}

Beyond the mere detection of humans, by their early stages of development, humans discriminate among individual conspesifics; neonates are able to differentiate strangers 
from their mothers (e.g., Bushnell, Sai, \& Mullin, 1989; Brooks-Gunn \& Lewis, 1981; Field, Cohen, Garcia, \& Greenberg, 1984; Pascalis, de Schonen, Morton, Deruelle, \& Fabre-Grenet, 1995).

Based on visual experiences, infants are able to identify the abstract properties of individuals beyond their discrete individuality; for example, infants exhibit a preference for individuals belonging to familiar categories such as race, sex, and species. The process of identifying is shaped by the exposure of individuals in the visual environment of the infants (de Schonen \& Mathivet, 1989; Morton \& Johnson, 1991; Nelson, 2001). With respect to race, 3-month-old infants are able to discriminate between own-race faces but not between other-race faces; however, infants could also discriminate between otherrace faces if they were familiarized with the faces of individuals from the other race (Sangrigoli \& de Schonen, 2004). While 3-month-old infants demonstrated spontaneous preference for faces from their own-ethnic group, neonates exhibited no spontaneous preference for faces from either their own- or other-ethnic groups (Kelly, Quinn, Slater, Lee, Gibson, Smith, Ge, \& Pascalis, 2005).

With regard to sex, it appears that young infants have consistently demonstrated preferences for prototypical female faces but not prototypical male faces (Kramer, Zebrowitz, Giovanni, \& Sherak, 1995). The differences in the extent and type of interaction of infants with their fathers and mothers might explain this selective preference. Mothers tend to remain the primary caretaker and they spend more time than fathers caring for their infants (Bailey, 1994; Jain, Belsky, \& Crnic, 1996; Russell \& Radojevic, 1992). With regard to the qualitative aspects, maternal interaction such as verbal interaction and a display of greater positive affect may direct the infant's attention towards his/her mother's face; however, paternal interaction, such as recreational activities involving limb movement, may direct the infant's attention towards his/her own body instead of towards the father's face (Forbes, Cohn, Allen, \& Lewinsohn, 2004; Golinkoff \& Ames, 1979; Landerholm \& Scriven, 1981; Yogman, 1981). The difference in the amount of visual experience with their mothers and fathers - with more experience with the mother than with the father-should result in a higher preference for female than male faces. In fact, a recent study supports this idea; infants of 3 months of age were observed to spontaneously prefer the faces of those of the same gender as their first caretaker during early infancy (Quinn, Yahr, Kuhn, Slater, \& Pascalis, 2002).

With regard to the attribute of species, from 6 months of age, infants retain the ability to discriminate among individuals of the species that they are exposed to most frequently; however, it is difficult for infants to discriminate among individuals of a species that they rarely observe. For instance, 6- and 9-month-old infants are able to discriminate among human individuals, while 6-month-old infants are additionally able to discriminate among individual monkeys (Pascalis, de Haan, \& Nelson, 2002). Nevertheless, 9-month-old infants exhibit their discrimination of individual monkeys provided that they were exposed to the faces of monkeys since 6 months of age (Pascalis, Scott, Kelly, Shannon, Nicholson, Coleman, \& Nelson, 2005).

The combined results of these studies on individual recognition and the processing of information such as race, sex and species, illustrate the critical role of visual experiences 
in the identification of others during infancy. Nevertheless, visual experiences do not explain the role of social perception during infancy; infants demonstrated a tendency to prefer their peers (other infants of the same age) over older children or adults when encountering other individuals; this was despite the fact that most infants must have had more visual experiences of viewing adults in their nurturing environment.

\section{Peer Preference in Infancy}

Previous studies have revealed that infants looked longer at photographs, drawings, and movies of other infants than at those of older children (Lewis \& Brooks, 1975; McCall \& Kennedy, 1980; Sanefuji, Ohgami, \& Hashiya, 2005). Infants expressed more positive affect by smiling, vocalizing, and gesturing more towards pictures and movies of other infants than to those of older children or adults (Lewis \& Brooks, 1975; Sanefuji et al., 2005). All these findings suggest that infants respond differently to individuals of various ages and that they prefer other infants to older children. Such preference during infancy is not explained by visual experiences, which therefore prompts the question, what is the basis of such peer preference.

\section{Two Kinds of Interpretation on Peer Preference}

One interpretation for this phenomenon is the preference for babyish characteristics. Lorenz (1943) suggested that the configuration of faces of the young ones in a variety of mammalian and avian species varies from their corresponding adult organisms in a similar manner. In comparison to an adult, babies have their eyes set at and below the midline of the face, a relatively large head and no protruding chin; further, the young ones move in a clumsy manner (Eibl-Eibesfeldt, 1975; Lorenz, 1943 as cited in Shaw \& Bransford, 1977). It is hypothesized that these infantile features, which are collectively referred to as the "baby schema," elicit positive affective responses and protective behavior. Moreover, it was observed that not only do infants prefer other infants to older children, but even among people of the same age, they prefer individuals with a baby face than those with a mature face. When 6-month-old infants were seated in front of 2 television monitors, they tended to look longer at the monitor that showed the photograph of an 18-year-old girl with a baby face than that showing a girl of the same age and attractiveness albeit with a mature face (Kramer, et al., 1995). Based on these findings, the result was interpreted as evidence for the emergence of selective preference for baby schemas during infancy.

Another interpretation is that infants prefer others who have similar features as themselves. Infants exhibited a looking preference for photographs and films of other same-sex infants (Aitken, 1977 as cited in Bower, 1989; Lewis \& Brooks, 1974). On presenting of PLDs of an infant boy and an infant girl on film, the first-fixation measure in the infants indicated significant preference for other infants belonging to the same sex (Kujawski \& Bower, 1993). Previous studies interpreted these findings as evidence of the ability to identify infants belonging to the same gender category, not only from feature cues but also from physical movements. A similar argument has been put forth in 
imitation studies; infants were capable of representing different types of sensory information on the basis of their ability to match their own behaviors with gestures performed by others (Meltzoff \& Moore, 1977, 1983, 1995). It is also possible that among infants of various ages, there is preference not only for the infants of the same sex but also for those of similar ages.

\section{Plausible Interpretation of Peer Preference}

Although the two interpretations for explaining peer preference are not mutually exclusive, there is no clear evidence indicating the more plausible interpretation. Sanefuji, Ohgami and Hashiya (2006a) attempted to answer this question by investigating whether 6- and 9-month-old infants responded differently to same-age infants from among older or younger infants, which might methodologically separate the two explanations for peer preference during infancy. Infants with a preference for baby schemas (as judged by adults), irrespective of their ages, are expected to prefer infants of a particular age with distinct babyish characteristics, such as an infant who is approximately 1 year old. Previous studies have suggested that baby schemas are most remarkable just before 1 year of age, which is likely to be adaptive as a releaser for caretaking behavior for infants who have just begun walking independently (Hildebrandt \& Fitzgerald, 1979; Negayama, 1997). On the other hand, infants with a preference for those similar to themselves are expected to prefer infants of the same age.

Sanefuji, et al. (2006a) revealed that only 9-month-old infants showed their preference while watching movies on infants of the same age when compared with watching movies of 12-month-old infants who are suggested to have distinct babyish characteristics (Experiment 1). The results indicate that 9-month-old infants might prefer others who are similar to themselves. They conducted subsequent experiments in order to explore the cause of the lack of such preference among 6-month-old infants and the key factor responsible for the selective preference among the 9-month-old infants.

\section{Cues of Preference for Peers of the Same Age}

Subsequently, Sanefuji et al. (2006a) conducted experiments to examine the possibility that the physical appearance of the stimuli (Experiment 2) and the visual activity of the particular stimulus (Experiment 3) functioned as cues for peer preference among infants. The results showed that both 6- and 9-month-old infants showed sensitivity to the photographs of other infants of the same age. Therefore, the sensitivity with respect to similarity to oneself appears to be the plausible explanation for peer preference among infants. On the other hand, the relative visual activity of a particular stimulus was not effective in eliciting different reactions from the 6- and 9-month-old participants. Nevertheless, this does not imply that body movements are non-significant in the identification of peers. The effect of movement patterns in eliciting peer preference has not been examined, because the movies transformed with mosaic patterns, which is used in Experiment 3 of Sanefuji et al. (2006a), distorted the qualitative features of the movements to the extent that they were not recognizable as human motion. In order to examine the possibility that the development of actions plays an important role in peer 
preference among infants, we must focus on the topic of movement pattern.

One suitable way to study the effect of movement pattern on peer preference is by conducting an experiment that uses PLDs focusing on locomotion development such as crawling and walking as the stimuli. Sanefuji et al. (2006b) investigated the developmental change in the perception of PLDs during infancy, particularly during the period when there is a marked change in the infant's locomotion from crawling to bipedal walking; the preference of crawling and walking infants to the PLDs of human crawlers and walkers was examined. If movement patterns indeed elicit peer preference, then crawling infants are expected to detect the PLDs of human crawlers while walking infants are expected to detect the PLDs of human walkers. Based on point-light information, the results indicated that both crawling and walking infants exhibited preference for the same type of locomotion as in themselves.

These results indicate that physical appearances as well as movement patterns are important cues for peer detection and peer preference during infancy.

\section{Correspondence Between Self and Others}

The results of infants' peer preference suggested that based on their developmental stage of processing information, 6- and 9-month-old infants showed sensitivity to other infants of the same age. Besides the ability to detect conspecifics and familiar individuals which had been revealed in various studies, recent study provide a new finding that infants are able to also detect relative values of similarity between the self and the other. This paper introduces this new perspective that the judgment of the similarity among conspesifics could be one critical cue to afford such detection, which should be associated with self-other recognition, cultural learning through imitation, and an understanding of mental states. Using cues of physical appearances and movement patterns, the infants' detection of similarity should be related to self-recognition. Previous researches have indicated that the visual recognition of the self on the basis of featural information emerges during the first 6 months of life (Bahrick, Moss \& Fadil, 1996) and that infants appear to be able to recognize their own visual appearances as familiar stimuli (Bahrick, 1995; Bahrick et al., 1996; Legerstee, Anderson, \& Schaffer, 1998). Peer preference during infancy forges important links between studies involvong self-recognition and social knowledge. It is possible that infants are able to detect similarity and experience familiarity toward infants of the same age infants based on self-recognition.

The imitative tendency of infants might also explain why they were more attracted to other infants of the same age. In order to reproduce the observed behaviors performed by other individuals, imitators have to adapt the particular behavior to their own body characteristics, which differ from those of the model. Studies with robots have suggested that it is difficult for a robot agent to adapt the imitated action to the current environment in which it is reproduced (Drescher, 1991; Kuniyoshi, Inaba, \& Inoue, 1994). However, infants do imitate various kinds of behaviors from the early stages of development (e.g., Field, Woodson, Greenberg, \& Cohen, 1982; Heimann, Nelson, \& Schaller, 1989; Meltzoff \& Moore, 1977, 1983, 1989; Reissland, 1988); they appear to be able to overcome the difficulty of having to expand cognitive costs in order to reproduce another 
individual's behavior. From among the models that infants imitate, the imitation of peers should involve the least cost for the interchange of behaviors because the imitator and imitatee share very similar body characteristics. As demonstrated in the previous study, body characteristics should serve as an important cue for such peer detection. On the basis of the imitative tendency during infancy (e.g., Meltzoff \& Moore, 1989), infants might detect and prefer individuals who are highly similar to themselves, that is, same-age peers.

\section{Self-OTher MAPPing: "LiKe Me” HyPothesis}

Such correspondence between the self and the other has recently aroused interest of developmental psychologist. Some researches assume that infants can recognize features that are "like me (see Note)" (Meltzoff \& Brooks, 2001; Meltzoff \& Moore, 1995). The self-other mappings, or the recognition of others as "like me," appear to emerge in the first day of life; facial imitation suggested that infants are aware of the correspondence between self and others.

\section{Facial Imitation}

Classical developmental theories had considered that facial imitation as a later achievement than imitation of hand movements and voices because infants are not able to visualize their own faces (Piaget, 1962). The studies that were conducted after Piaget (1962) have revealed newer aspects regarding the ability to imitate during infancy; across all cultures, infants, even neonates, could imitate a range of facial imitation (e.g., Field, et al., 1982; Fontaine, 1984; Heimann et al., 1989; Meltzoff \& Moore, 1977, 1983; Reissland, 1988).

Meltzoff and Moore (1977) investigated facial imitation of 12- to 21-day-old infants; 2 types of lip movements (lip opening versus lip protrusion) and 2 types of protrusion actions (lip protrusion versus tongue protrusion) were demonstrated. In response, infants responded differently to lip opening with lip opening but not to lip protrusion. Likewise, they responded differently to tongue protrusion with tongue protrusion but not lip protrusion. These results suggested that infants imitated 2 different movements of the same body part as well as the same movements of 2 different body parts differently; there was no confusion regarding either the side of movement or the side of body part. This revealed that the infants were able to identify the specific organ that needed to be imitated (Meltzoff \& Moore, 1977). It should be noted that this phenomenon is not a general reaction to the mere presence of humans, because the same human face was demonstrated in all conditions. Such facial imitation is also observed in neonates (Meltzoff \& Moore, 1983, 1989); the mean age of the participants was 32 hours, and the youngest participant was 42 minutes old. Facial imitation by neonates should imply an innate mapping

\footnotetext{
Note

Meltzoff et al. (1998) noted using the English word "me." They do not suggest that the infant has the fullfledged adult sense of self, which should be a developmental product. One argument could be rephrased by purging the "me" word and instead saying, "That looks like this feels."
} 
between the observation and execution of human actions.

Meltzoff and Moore proposed that facial imitation is based on active intermodal mapping (AIM) (Meltzoff \& Moore, 1994, 1995, 1997). According to AIM, motor performance in infants could be evaluated against the observed movement through the proprioceptive feedback loop, because the observation and execution of human actions are coded within a common framework. This view is consistent with the findings in neuroscience concerning shared neural substrates for perception and action, which is known as the mirror neuron system (e.g., Decety, 2002; Iacoboni, Woods, Brass, Bekkering, Mazziotta, \& Rizzolatti, 1999; Rizolatti, Fogassi, \& Gallese, 2001). Facial imitation indicates that even neonates could map actions they see being performed by others onto those performed by their own body. Human actions are particularly relevant to infants because they appear to the infant as it experiences itself to be and because they are events that infants can intend (Meltzoff, 2005).

In this manner, human infants seem to detect other humans as "like me" individuals, in other words, as conspecifics (Meltzoff, Gopnik, \& Repacholi, 1998). The world of material objects is then divisible into those that perform human actions and those do not. Sanefuji et al. (2006a, 2006b) extended these views by stating that in addition to detecting conspecifics, infants might also detect relative values of similarity between themselves and others.

\section{TOWARD Understanding Mental States in OTHERs: Links With Early Social Perception}

Thus far, previous findings have shown that since their birth, infants respond to human's behaviors by exhibiting a looking preference and imitating that behavior of their own. Human beings are the only entities in the world with whom infants can share their behavioral states (Meltzoff \& Brooks, 2001).

The imitation of infants by others should be the most emphatic behaviors with regard to "like me" recognition; it is equally true in this case that the infants" behavior and that of the others' are equivalent. Imitating infant's behavior is crucial in social cognitive development because it is a recognized exchange between two individuals and it creates a feeling of mutual understanding between them (Nadel \& Peze, 1993), which provides a basis for the infants to attribute similar mental states to others (Meltzoff, et al., 1999). In typical development, toddlers selectively looked and smiled more often at the person who imitated them (Field, 1977; Gergely, 2001; Meltzoff, 1990). Further, during early preschool age, children are particularly responsive to imitations of their own behaviors (Lubin \& Field, 1981). These findings indicate that infants are able to recognize and appreciate the fact that the behaviors of the self and those of others have the same form/ manner; the adult is behaving "just like me," not merely "just when I act." This could perhaps explain the use of imitation as a strategy to attract and maintain their infants' attention (Trevarthen \& Hubley, 1978); further, across all cultures, imitation is included in the daily interactions of adults with their infants (Brazelton \& Tronick, 1980; Bruner, 
1975, 1983; Stern, 1985; Trevarthen, 1977). Even before speaking, infants appear to notice this recognized, mutual contact with others.

Pervasive developmental disorder (PDD) including autism is characterized by the qualitative lacks of social initiative and reciprocity (e.g., Hobson, 1993; Rutter, 1983). Imitating children with PDD should be fairly effective in facilitating their joint attention skills and social interaction because mutual imitation games are an important constituent of early interpersonal growth. In fact, experimental imitation of the procedural use of an object resulted in increased positive attention toward the experimenter and object manipulation (Dawson \& Adams, 1984; Tiegerman \& Primavera, 1981, 1984). Nadel, Croue, Kervella, Mattlinger, Canet, Hudelot, Lecuyer, and Martini (2000) investigated the responses of children with autism after an adult imitated their actions by using the adapted still-face paradigm (Tronick, Als, Adamson, Wise, \& Brazelton, 1978). According to the results, when compared with the still-face session before the imitation session, the children in the still-face session after the imitation session showed significantly more expectant behaviors such as looking or touching, which is a rare occurrence among children with autism. These findings suggest that imitating children with PDD is useful as an introduction to initiating social relationships with people.

The "like me" hypothesis highlights the matching physical movements and not merely temporal contingency. According to this hypothesis, the recognition of the correspondence between movements produced by self and those produced by others should have extended developmental consequences. This paper might emphasize the importance of the ability to detect relative values of similarity between the self and the other among conspecifics during infancy, in addition to the "like me" stance (the ability to detect the conspecifics), raised by previous findings, for recognition of the generality and individuality of other's mental states. When infants detect "like-me" individuals and observe others behave "like me" (i.e., producing identical expressions and movements), they infer that the others have mental experiences that are linked to those behaviors in the self (Meltzoff, 2004). This provides the infant with a deeper understanding of the mental states underlying the physical movements of other individual because the infant is able to associate the mental state with his/her own intentionality. Infants have experienced their own emotions, desire, and intentional action by trial and error. Such experiences would suggest that there is a goal beyond the surface behavior. Thus, physical similarity including in the structure of imitating child might facilitate the development of joint attention skills and an understanding of the other's intention.

Recognition of "like me" features has an important impact on social cognitive development during infancy; the empirical findings on "like me" detections have not only revolutionized a variety of traditional assumptions, but they have also played a part in clinical application. However, it should be noted that the infants' social perception is not the sole factor in subsequent social cognitive development. The psychological characteristics with which a child is born are modified by and become adapted to the social world; in addition, relationships with peers or caretakers play an important role in social development. While the present article reviews the social perception of infants, but the promotion of mutual understanding and developmental changes of reciprocity between 
infants and their social partners should be discussed as one of the subsequent areas for further study.

\section{REFERENCES}

Adamson, L., \& Bakeman, R. 1985. Affect and attention: Infants observed with mothers and peers. Child Development, 56, 582-593.

Aitken, S. 1977. Gender Preference in Infancy. M. A. thesis, University of Edinburgh. Cited in T. G. R. Bower (Ed.). 1989. Rational infant: Learning in infancy. New York: W. H. Freeman and Company.

Bahrick, L. E. 1995. Intermodal origins of self-perception. In P. Rochat (Ed.), The self in infancy: Theory and research. Amsterdam: North Holland-Elsevier.

Bahrick, L. E., Moss, L., \& Fadil, C. 1996. Development of visual self-recognition in infancy. Ecological Psychology, 8, 189-208.

Bailey, W. T. 1994. A longitudinal study of fathers' involvement with young children: Infancy to age 5 years. Journal of Genetic Psychology, 155, 331-339.

Bellagamba, F., \& Tomasello, M. 1999. Re-enacting intended acts: comparing 12- and 18-month-olds. Infant Behavior and Development, 22, 277-282.

Bertenthal, B. I. 1993. Infants' perception of biomechanical motions: intrinsic image and knowledge-based constraints. In C. Granrud (Ed.), Visual perception and cognition in infancy. Erlbaum, Hillsdale, NJ.

Bertenthal, B. I., Proffitt, D. R., \& Cutting, J. E. 1984. Infant sensitivity to figural coherence in biomechanical motions. Journal of Experimental Child Psychology, 37, 213-230.

Bertenthal, B. I., Proffitt, D. R., \& Kramer, S. J. 1987. The perception of biomechanical motions by infants: implementation of various processing constraints. Journal of Experimental Psychology, 13, 577-585.

Bertenthal, B. I., Proffitt, D. R., Spetner, N. B., \& Thomas, M. A. 1985. The development of infant sensitivity to biomechanical motions. Child Development, 56, 531-543.

Brazelton, T. B., \& Tronick, E. 1980. Preverbal communication between mothers and infants. In D. R. Olson (Ed.), The social foundations of language and thought. New York: Norton.

Brooks-Gunn, J., \& Lewis, M. 1981. Infant social perception: Responses to pictures of parents and strangers. Developmental Psychology, 17, 647-649.

Brooks, R., \& Meltzoff, A. N. 2002. The importance of eyes: How infants interpret adult looking behavior. Developmental Psychology, 38, 958-966.

Bruner, J. S. 1975. From communication to language - A psychological perspective. Cognition, 3, $255-287$.

Bruner, J. S. (Ed.) 1983. Child's talk: Learning to use language. New York: Norton.

Bruner, J. S. 1995. From joint attention to the meeting of minds. In C. Moore \& P. J. Dunham (Eds.), Joint attention: Its origins and role in development. Hillsdale, NJ: Lawrence Erlbaum Associates.

Bushnell, I. W. R., Sai, F., \& Mullin, J. T. 1989. Neonatal recognition of the mother's face. British Journal of Developmental Psychology, 7, 3-15.

Butterworth, G. E., \& Jarrett, N. L. M. 1991. What minds have in common is space: Spatial mechanisms serving joint visual attention in infancy. British Journal of Developmental Psychology, 9, 55-72.

Carpenter, M., Nagell, K., \& Tomasello, M. 1998. Social cognition, joint attention, and communicative competence from 9 to 15 months of age. Monographs of the Society for Research in Child Development, 63 (4, Serial No. 255), 1-143.

Dawson, G., \& Adams, A. 1984. Imitation and social responsiveness in autistic children. Journal of Abnormal Child Psychology, 12, 209-226.

Decety, J. 2002. Is there such a thing as functional equivalence between imagined, observed, and executed action? In A. N. Meltzoff \& W. Prinz (Eds.), The imitative mind: Development, evolution, and brain bases. Cambridge: Cambridge University Press.

de Schonen, S., \& Mathivet, H. 1989. First come, first served: a scenario about the development of hemispheric specialisation of face recognition during early infancy. European Bulletin of Cognitive Psychology, 9, 3-44.

Drescher, G. L. (Ed.) 1991. Made-up minds: A constructivist approach to artificial intelligence. Cambridge, 
MA: MIT Press.

Eibl-Eibesfeldt, I. (Ed.) 1975. Ethology: The biology of behaviour. New York: Holt, Rinehart, \& Winston.

Fantz, R. L. 1963. Pattern vision in newborn infants. Science, 140, 296-297.

Field, T. M. 1977. Effects of early separation, interactive deficits, and experimental manipulations on infantmother face-to-face interaction. Child Development, 48, 763-771.

Field, T. M., Cohen, D., Garcia, R., \& Greenberg, R. 1984. Mother-stranger face discrimination by the newborn. Infant Behavior and Development, 7, 19-25.

Field, T. M., Woodson, R., Greenberg, R., \& Cohen, D. 1982. Discrimination and imitation of facial expressions by neonates. Science, 218, 179-181.

Fontaine, R. 1984. Imitative skills between birth and six months. Infant Behavior and Development, 7, 323333.

Forbes, E. E., Cohn, J. F., Allen, N. B., \& Lewinsohn, P. M. 2004. Infant affect during parent-infant interaction at 3 and 6 months: Differences between mothers and fathers and influence of parent history of depression. Infancy, 5, 61-84.

Fox, R., \& Mcdaniel, C. 1982. The perception of biological motion by human infants. Science, 218, 467486.

Gergely, G. 2001. The obscure object of desire: 'nearly, but clearly not, like me': contingency preference in normal children versus children with autism. Bulletin of Menninger Clinic, 65, 411-426.

Golinkoff, R. M., \& Ames, G. J. 1979. A comparison of fathers' and mothers' speech with their young children. Child Development, 50, 28-32.

Gopnik, A., \& Meltzoff, A. N. (Eds.) 1997. Words, thoughts, and theories. Cambridge, MA: MIT Press.

Heimann, M., Nelson, K. E., \& Schaller, J. 1989. Neonatal imitation of tongue protrusion and mouth opening: methodological aspects and evidence of early individual differences. Scandinavian Journal of Psychology, 30, 90-101.

Hildebrandt, K. A., \& Fitzgerald, H. E. 1979. Facial feature determinants of perceived infant attractiveness. Infant Behavior and Development, 2, 329-339.

Hirai, M. \& Hiraki, K. 2005. An event-related potentials study of biological motion perception in human infants. Cognitive Brain Research, 22, 301-304.

Hobson, R. P. (Ed.) 1993. Autism and the development of mind. Hillsdale: Lawrence Erlbaum Assoc.

Iacoboni, M., Woods, R. P., Brass, M., Bekkering, H., Mazziotta, J. C., \& Rizzolatti, G. 1999. Cortical mechanisms of human imitation. Science, 286, 2526-2528.

Jain, A., Belsky, J., \& Crnic, K. 1996. Beyond fathering behaviors: Types of dads. Journal of Family Psychology, 10, 431-442.

Johnson, M. H., Dziurawiec, S., Ellis, H., \& Morton, J. 1991. Newborns' preferential tracking of face-like stimuli and its subsequent decline. Cognition, 40, 1-19.

Kelly, D. J., Quinn, P. C., Slater, A. M., Lee, K., Gibson, A., Smith, M., Ge, L., \& Pascalis, O. 2005. Threemonth-olds, but not newborns, prefer own-race faces. Developmental Science, 8, F31-F36.

Kramer, S., Zebrowitz, L. A., Giovanni, J. P. S., \& Sherak, B. 1995. Infant preferences for attractiveness and babyfaceness. In B. G. Bardy, R. J. Bootsme, \& Y. Guiard (Eds.), Studies in perception and action III. Hillsdale, NJ: Erlbaum Associates.

Kujawski, J. H., \& Bower, T. G. R. 1993. Same-sex preferential looking during infancy as a function of abstract representation. British Journal of Developmental Psychology, 11, 201-209.

Kuniyoshi, Y., Inaba, M., \& Inoue, H. 1994. Learning by watching: Extracting reusable task knowledge from visual observation of human performance. IEEE Transactions on Robotics and Automation, 10, 799 822 .

Landerholm, E. J., \& Scriven, G. 1981. A comparison of mother and father interaction with their six-monthold male and female infants. Early Child Development and Care, 7, 317-328.

Legerstee, M. 1992. A review of the animate-inanimate distinction in infancy: Implications for models of social and cognitive knowing. Early Development and Parenting, 1, 59-67.

Legerstee, M., Anderson, D., \& Schaffer, A. 1998. Five- and eight-month-old infants recognize their faces and voices as familiar and social stimuli. Child Development, 69, 37-50.

Lewis, M., \& Brooks, J. 1974. Self, other, and fear: Infants' reactions to people. In M. Lewis \& L. A. Rosenblum (Eds.), The origins of fear: the origins of behavior. New York: Wiley.

Lewis, M., \& Brooks, J. 1975. Infants' social perception: A constructivist view. In L. B. Cohen, P. Salapatek, 
(Eds.), Infant perception: From sensation to cognition. New York: Academic Press.

Lorenz, K. Z. 1943. Die angeborenen Formen möglicher Erfahrung. Zeitschrift für Tierpsychologie, 5, 235409. Cited in R. Shaw \& J. Bransford (Eds.), 1977. Perceiving, acting, and knowing: Toward an ecological psychology (pp. 125). Hillsdale, NJ: Erlbaum.

Lubin, L., \& Field, T. 1981. Imitation during preschool peer interaction. International Journal of Behavioral Development, 4, 443-453.

Maurer, D., \& Young, R. E. 1983. Newborn's following of natural and distorted arrangements of facial features. Infant Behavior and Development, 6, 127-131.

McCall, R. B., \& Kennedy, C. B. 1980. Attention of 4-month infants to discrepancy and babyishness. Journal of experimental child psychology, 29, 189-201.

Meltzoff, A. N. 1990. Foundations for developing a concept of self: The role of imitation in relating self to other and the value of social mirroring, social modeling, and self practice in infancy. In D. Cicchetti \& M. Beeghly (Eds.), The self in transition: infancy to childhood. University of Chicago Press.

Meltzoff, A. N. 1995. Understanding the intentions of others: Re-enactment of intended acts by 18-monthold children. Developmental Psychology, 31, 838-850.

Meltzoff, A. N. 2004. The case for developmental cognitive science: theories of people and things. In G. Bremner \& A. Slater (Eds.), Theories of infant development. Blackwell Publishing.

Meltzoff, A. N. 2005. Imitation and other minds: the "like me" hypothesis. In S. Hurley \& N. Chater (Eds.), Perspectives on imitation: From neuroscience to social science. Cambridge, MA: MIT Press.

Meltzoff, A. N., \& Brooks, R. 2001. "Like me" as a building block for understanding other minds: Bodily acts, attention, and intention. In B. F. Malle, L. J. Moses, \& D. A. Baldwin (Eds.), Intentions and intentionality: Foundations of social cognition. Cambridge, Massachusetts: The MIT Press.

Meltzoff, A. N., \& Gopnik, A. 1993. The role of imitation in understanding persons and developing a theory of mind. In S. Baron-Cohen, H. Tager-Flusberg, \& D. J. Cohen (Eds.), Understanding other minds: Perspectives from autism. New York: Oxford University Press.

Meltzoff, A. N., Gopnik, A., \& Repacholi, B. M. 1998. Toddlers' understanding of intentions, desires, and emotions: Explorations of the dark ages. In P. D. Zelazo, J. W. Astington, \& D. R. Olson (Eds.), Developing theories of intention: social understanding and self-control. Mahwah, NJ: Lawrence Erlbaum Associates.

Meltzoff, A. N., \& Moore, M. K. 1977. Imitation of facial and manual gestures by human neonates. Science, 198, 75-78.

Meltzoff, A. N., \& Moore, M. K. 1983. Mewborn infants imitate adult facial gestures. Child Development, 54, 702-709.

Meltzoff, A. N., \& Moore, M. K. 1989. Imitation in newborn infants: Exploring the range of gestures imitated and the underlying mechanisms. Developmental Psychology, 25, 954-962.

Meltzoff, A. N., \& Moore, M. K. 1994. Imitation, memory, and the representation of persons. Infant Behavior and Development, 17, 83-99.

Meltzoff, A. N., \& Moore, M. K. 1995. A theory of the role of imitation in the emergence of self. In P. Rochat (Ed.), The self in early infancy: Theory and research. New York: North-Holland.

Meltzoff, A. N., \& Moore, M. K. 1997. Explaining facial imitation: A theoretical model. Early Development and Parenting, 6, 179-192.

Mervis, C. B., \& Rosch, E. 1981. Categorization of natural objects. In M. R. Rosenzweig \& L. W. Porter (Eds.), Annual Review of Psychology. (Vol. 32, pp. 89-115). Palo Alto, CA.

Molina, M., Van de Walle, G. A., Condry, K., \& Spelke, E. S. 2004. The animate-inanimate distinction in infancy: Developing sensitivity to constraints on human actions. Journal of cognition and development, 5, 399-426.

Morales, M., Mundy, P., Delgado, C. E. F., Yale, M., Neal, R., \& Schwartz, H. K. 2000. Gaze following, temperament, and language development in 6-months olds: A replication and extension. Infant Behavior and Development, 21, 373-377.

Morales, M., Mundy, P., \& Rojas, J. 1998. Brief report: Following the direction of gaze and language development in 6-month-olds. Infant Behavior and Development, 21, 373-377.

Morton, J., \& Johnson, M. H. 1991. CONSPEC and CONLERN: A two-process theory of infant face recognition. Psychological Review, 98, 164-181.

Mundy, P., \& Gomes, A. 1998. Individual differences in joint attention skill development in the second year. 
Infant Behavior and Development, 21, 469-482.

Nadel, J., Croue, S., Kervella, C., Mattlinger, M. J., Canet, P., Hudelot, C., Lecuyer, C., \& Martini, M. 2000. Do autistic children have ontological expectancies concerning human behavior? Autism, 4, 133-145.

Nadel, J., \& Peze, A. 1993. What makes immediate imitation communicative in toddlers and autistic children? In J. Nadel \& L. Camaioni (Eds.), New perspectives in early communicative development. London, NY: Routledge.

Negayama, K. 1997. A study of longitudinal change in cuteness of children's faces (in Japanese). Waseda studies in human sciences, 10, 61-68.

Nelson, C. A. 2001. The development and neural bases of face recognition. Infant and Child Development, 10, 3-18.

Pascalis, O., de Haan, M., \& Nelson, C. A. 2002. Is face processing species-specific during the first year of life? Science, 296, 1321-1323.

Pascalis, O., de Schonen, S., Morton, J., Deruelle, C., \& Fabre-Grenet, M. 1995. Mother's face recognition by neonates: A replication and an extension. Infant Behavior and Development, 18, 79-95.

Pascalis, O., Scott, L. S., Kelly, D. J., Shannon, R. W., Nicholson, E., Coleman, M., \& Nelson, C. A. 2005. Plasticity of face processing in infancy. Proceedings of the National Academy of Science of the USA, 102, 5297-5300.

Piaget, J. (Ed.) 1962. Play, dreams and imitation in childhood. Norton, New York.

Poulin-Dubois, D. 1999. Infant's distinction between animate and inanimate objects: The origin of native psychology. In P. Rochat (Ed.), Early social cognition: understanding others in the first months of life. Mahwah, NJ: Lawrence Erlbaum Associates.

Proffitt, D. R., \& Bertenthal, B. I. 1990. Converging operations revisited: assessing what infants perceive using discrimination measures, Perception and Psychophysics, 47, 1-11.

Puce, A., \& Perrett, D. I. 2003. Electrophysiology and brain imaging of biological motion. Philosophical Transactions: Biological Sciences, 358, 435-445.

Quinn, P. C., Yahr, J., Kuhn, A., Slater, A. M., \& Pascalis, O. 2002. Representation of the gender of human faces by infants: A preference for female. Perception, 31, 1109-1121.

Reid, V. M., Hoehl, S. \& Striano, T. 2006. The perception of biological motion by infants: An event related potential study, Neuroscience Letter, 395, 211-214.

Reissland, N. 1988. Neonatal imitation in the first hour of life: observations in rural Nepal. Developmental Psychology, 24, 464-469.

Rizzolatti, G., Fogassi, L., \& Gallese, V. 2001. Neurophysiological mechanisms underlying the understanding and imitation of action. Nature Reviews Neuroscience, 2, 661-670.

Russell, G., \& Radojevic, M. 1992. The changing role of fathers? Current understandings and future directions for research and practice. Infant Mental Health Journal, 13, 296-311.

Rutter, M. 1983. Cognitive deficits in the pathogenesis of autism. Journal of Child Psychology and Psychiatry, 24, 513-531.

Sanefuji, W., Hashiya, K., Itakura, S., \& Ohgami, H. 2004. Emergence of the understanding of the other's intention: Re-enactment of intended acts from "failed-attempts" in 12- to 24-month olds. Psychologia, 47, 10-17.

Sanefuji, W., Ohgami, H., \& Hashiya, K. 2005. Infants' preference for infants and adults. Proceedings of $20054^{\text {th }}$ IEEE International Conference on Development and Learning, 93-95.

Sanefuji, W., Ohgami, H., \& Hashiya, K. 2006a. Preference for peers in infancy. Infant Behavior and Development, 29, 584-593.

Sanefuji, W., Ohgami, H., \& Hashiya, K. 2006b. Preference for the relevant type pf locomotion in infancy. The Japanese Journal of Psyconomic Science, 25, 123-124.

Sangrigoli, S., \& de Schonen, S. 2004. Recognition of own-race and other-race faces by three-month old infants. Journal of Child Psychology and Psychiatry, 45, 1-9.

Saxe, R., Xiao, D. K., Kovacs, G., Perrett, D. I., \& Kanwisher, N. 2004. A region of right posterior superior temporal sulcus responds to observed intentional actions. Neuropsychologia, 42, 1435-1446.

Sorce, J. F., Emde, R. N., Campos, J. J., \& Klinnert, M. D. 1985. Maternal emotional signalling: its effects on the visual cliff behavior of 1-year-olds. Developmental Psychology, 21, 195-200.

Stern, D. N. (Ed.) 1985. The interpersonal world of the infant: A view from psychoanalysis and developmental psychology. New York: Basic Books. 
Tiegerman, E., \& Primavera, L. 1981. Object manipulation: An interactional strategy with autistic children. Journal of Autism and Developmental Disorders, 11, 427-438.

Tiegerman, E., \& Primavera, L. H. 1984. Imitating the autistic child: Facilitating communicative gaze behavior. Journal of Autism and Developmental Disorders, 14, 27-38.

Tomasello, M. 1995. Joint attention as social cognition. In C. Moore \& P. J. Dunham (Eds.), Joint attention: Its origins and role in development. Hillsdale, NJ: Lawrence Erlbaum Associates.

Tomasello, M., Call, J., \& Hare, B. 2003. Chimpanzees understand psychological states - the question is which ones and to what extent. TRENDS in Cognitive Sciences, 7, 153-156.

Tomasello, M., \& Farrar, M. J. 1986. Joint attention and early language. Child Development, 57, 1454-1463.

Trevarthen, C. 1977. Descriptive analysis of infant communicative behavior. In H. R. Schaffer (Ed.) Studies in mother-infant interaction. London: Academic Press.

Trevarthen, C., \& Hubley, P. 1978. Secondary intersubjectivity: Confiding and acts of meaning in the first year. In A. Lock (Ed.), Action, gesture and symbol. London: Academic Press.

Tronick, E., Als, H., Adamson, L., Wise, S., \& Brazelton, T. 1978. The infant's response to entrapment between contradictory messages in face-to-face interaction. Journal of American Academy of Child Psychiatry, 17, 1-13.

Valenza, E., Simion, F., Macchi Cassia, V., \& Umiltà, C. 1996. Face preference at birth. Journal of Experimental Psychology: Human Perception and Performance, 22, 892-903.

von Hofsten, C., \& Siddiqui, A. 1993. Using the mother's actions as a reference for object exploration in 6and 12-month-old infants. British Journal of Developmental Psychology, 11, 61-74.

Yogman, M. W. 1981. Games fathers and mothers play with their infants. Infant Mental Health Journal, 2, 241-248. 